\title{
Genome-wide analysis of HSP70 family genes in cabbage (Brassica oleracea var. capitata) reveals their involvement in floral development
}

\author{
Henan Su${ }^{\dagger}$, Miaomiao Xing ${ }^{\dagger}$, Xing Liu, Zhiyuan Fang, Limei Yang, Mu Zhuang, Yangyong Zhang, Yong Wang and
} Honghao LV ${ }^{*}(D)$

\begin{abstract}
Background: Heat shock proteins have important functions in regulating plant growth and response to abiotic stress. HSP70 family genes have been described in several plant species, but a comprehensive analysis of the HSP70 family genes in cabbage has not been reported to date, especially their roles in floral development.

Results: In this study, we identified 52 BoHSP70 genes in cabbage. The gene structures, motifs, and chromosome locations of the BoHSP70 genes were analyzed. The genes were divided into seven classes using a phylogenetic analysis. An expression analysis showed that the BOHSP70 genes were highly expressed in actively growing tissues, including buds and calluses. In addition, six BOHSP70 genes were highly expressed in the binuclear-pollen-stage buds of a male fertile line compared with its near isogenic sterile line. These results were further verified using qRT-PCR. Subcellular localization analysis of the bud-specific gene BoHSP70-5 showed that it was localized in the cytoplasm.
\end{abstract}

Conclusions: Our results help to elucidate the involvement of the BOHSP7O family genes in cabbage floral development and establish the groundwork for future research on the functions of these genes.

Keywords: Cabbage, Genome-wide, HSP70 family genes, Expression profiling

\section{Background}

HSP70, a type of heat shock protein (HSP), has long been recognized as one of the most conserved protein families, which can respond to external environmental stimuli and improve the ability of the organism to adjust to an adverse environment [1-3]. HSP70s function as molecular chaperones, presumably by protecting proteins against aggregation based on their ability to bind to hydrophobic amino acid residues or surfaces that are exposed by proteins in nonnative states. HSP70s are found in almost all organisms and are highly conserved [4-6]. Under normal conditions, the heat shock protein accounts for approximately $5 \%$ of the total cellular protein,

\footnotetext{
* Correspondence: Ivhonghao@caas.cn

${ }^{\dagger}$ Henan Su and Miaomiao Xing contributed equally to this work. Institute of Vegetables and Flowers, Chinese Academy of Agricultural Sciences, Key Laboratory of Biology and Genetic Improvement of Horticultural Crops, Ministry of Agriculture, Beijing 100081, China
}

but when the organism is subjected to environmental stress, especially high temperature conditions, it can account for up to $15 \%$ of the total cell protein [7]. HSPs can be divided into five families: HSP100, HSP90, HSP70, HSP60 and sHSP based on their molecular weights; among them, the HSP70 family is the most widely distributed HSP in vivo, which is not only the most studied but also the most conservative in terms of evolution [8]. The HSP70 family has drawn the greatest attention, because it is fundamental to plant developmental processes and functions during heat stress when the organism is subjected to external stress [9].

Many studies have shown that HSP70 is closely related to plant abiotic stress [10], disease resistance [11], and growth and development [12]. When the plant suffers from high temperature, drought, high salt, low temperature, and heavy metals, HSP70s rapidly accumulate to maintain the stability

(c) The Author(s). 2019 Open Access This article is distributed under the terms of the Creative Commons Attribution 4.0 International License (http://creativecommons.org/licenses/by/4.0/), which permits unrestricted use, distribution, and 
Table 1 HSP70 family genes in the cabbage genome

\begin{tabular}{|c|c|c|c|c|c|c|c|}
\hline \multirow[t]{2}{*}{ No. } & \multirow[t]{2}{*}{ Gene ID } & \multirow[t]{2}{*}{ Name } & \multirow{2}{*}{$\begin{array}{l}\text { Protein } \\
\text { Length (aa) }\end{array}$} & Gene & Chr & \multirow[t]{2}{*}{ Tandem } & \multirow[t]{2}{*}{$\begin{array}{l}\text { Localization } \\
\text { predicted }\end{array}$} \\
\hline & & & & \multicolumn{2}{|l|}{ Length (bp) } & & \\
\hline 1 & Bol029014 & BoHSP70-1 & 896 & 4901 & $\mathrm{C} 01$ & NO & Mit \\
\hline 2 & Bol009554 & BoHSP70-2 & 437 & 2912 & $\mathrm{CO1}$ & YES & $\mathrm{Chl}$ \\
\hline 3 & Bol009553 & BoHSP70-3 & 414 & 2895 & $\mathrm{C} 01$ & YES & Mit \\
\hline 4 & Bol039526 & BoHSP70-4 & 370 & 1762 & $\mathrm{CO1}$ & NO & Cyt \\
\hline 5 & Bol018771 & BoHSP70-5 & 377 & 1622 & $\mathrm{C} 01$ & NO & Cyt \\
\hline 6 & Bol036512 & BoHSP70-6 & 280 & 2355 & $\mathrm{CO} 1$ & NO & Mit \\
\hline 7 & Bol030974 & BoHSP70-7 & 377 & 1377 & $\mathrm{C} 01$ & NO & Cyt \\
\hline 8 & Bol007329 & BoHSP70-8 & 271 & 2384 & $\mathrm{CO} 1$ & NO & Mit \\
\hline 9 & Bol023082 & BoHSP70-9 & 354 & 1855 & $\mathrm{C} 01$ & NO & $\mathrm{N}$ \\
\hline 10 & Bol024627 & BoHSP70-10 & 377 & 1376 & $\mathrm{CO2}$ & NO & Cyt \\
\hline 11 & Bol015484 & BoHSP70-11 & 377 & 1668 & $\mathrm{CO} 2$ & NO & $\mathrm{N}$ \\
\hline 12 & Bol012377 & BoHSP70-12 & 259 & 861 & $\mathrm{CO} 2$ & NO & Cyt \\
\hline 13 & Bol008775 & BoHSP70-13 & 377 & 1397 & $\mathrm{CO3}$ & NO & Cyt \\
\hline 14 & Bol025936 & BoHSP70-14 & 651 & 3666 & $\mathrm{CO3}$ & NO & Cyt \\
\hline 15 & Bol004630 & BoHSP70-15 & 373 & 2724 & $\mathrm{CO3}$ & NO & ER \\
\hline 16 & Bol005557 & BoHSP70-16 & 588 & 2627 & $\mathrm{CO3}$ & NO & ER \\
\hline 17 & Bol005539 & BoHSP70-17 & 377 & 1739 & $\mathrm{CO3}$ & NO & Cyt \\
\hline 18 & Bol022870 & BoHSP70-18 & 377 & 1299 & $\mathrm{CO3}$ & NO & Cyt \\
\hline 19 & Bol041394 & BoHSP70-19 & 377 & 1433 & $\mathrm{CO3}$ & NO & Cyt \\
\hline 20 & Bol032741 & BoHSP70-20 & 613 & 1985 & $\mathrm{CO3}$ & NO & Mit \\
\hline 21 & Bol035016 & BoHSP70-21 & 466 & 3337 & $\mathrm{CO3}$ & NO & Cyt \\
\hline 22 & Bol025569 & BoHSP70-22 & 377 & 2531 & $\mathrm{CO} 4$ & NO & Cyt \\
\hline 23 & Bol044280 & BoHSP70-23 & 259 & 1545 & $\mathrm{CO} 4$ & NO & Mit \\
\hline 24 & Bol014092 & BoHSP70-24 & 563 & 1692 & $\mathrm{CO} 4$ & NO & Mit \\
\hline 25 & Bol025245 & BoHSP70-25 & 377 & 1290 & $\mathrm{CO} 4$ & NO & Cyt \\
\hline 26 & Bol030773 & BoHSP70-26 & 692 & 6667 & $\mathrm{C} 05$ & NO & Cyt \\
\hline 27 & Bol010298 & BoHSP70-27 & 365 & 2280 & C05 & NO & Cyt \\
\hline 28 & Bol010299 & BoHSP70-28 & 107 & 324 & $\mathrm{C} 05$ & NO & Cyt \\
\hline 29 & Bol010323 & BoHSP70-29 & 377 & 1688 & $\mathrm{C} 05$ & NO & Cyt \\
\hline 30 & Bol005376 & BoHSP70-30 & 377 & 1438 & C06 & NO & Cyt \\
\hline 31 & Bol031604 & BoHSP70-31 & 377 & 1413 & $\mathrm{C} 06$ & NO & Cyt \\
\hline 32 & Bol042853 & BoHSP70-32 & 360 & 2336 & $\mathrm{CO}$ & NO & Cyt \\
\hline 33 & Bol042165 & BoHSP70-33 & 433 & 2957 & $\mathrm{CO}$ & NO & $\mathrm{Chl}$ \\
\hline 34 & Bol013215 & BoHSP70-34 & 331 & 3699 & $\mathrm{C} 08$ & NO & Cyt \\
\hline 35 & Bol025147 & BoHSP70-35 & 377 & 1552 & $\mathrm{C} 08$ & NO & Cyt \\
\hline 36 & Bol045633 & BoHSP70-36 & 357 & 1568 & C08 & NO & Cyt \\
\hline 37 & Bol006580 & BoHSP70-37 & 395 & 2536 & $\mathrm{C} 08$ & NO & ER/Mit/N \\
\hline 38 & Bol032207 & BoHSP70-38 & 389 & 2732 & C09 & NO & Cyt \\
\hline 39 & Bol017308 & BoHSP70-39 & 586 & 4491 & C09 & NO & Cyt \\
\hline 40 & Bol043724 & BoHSP70-40 & 377 & 1394 & C09 & NO & Cyt \\
\hline 41 & Bol041704 & BoHSP70-41 & 377 & 1396 & Scaffold000009_P1 & NO & Cyt \\
\hline 42 & Bol037535 & BoHSP70-42 & 363 & 1795 & Scaffold000024 & NO & Cyt \\
\hline 43 & Bol036345 & BoHSP70-43 & 301 & 2723 & Scaffold000029 & NO & $E R / N$ \\
\hline
\end{tabular}


Table 1 HSP70 family genes in the cabbage genome (Continued)

\begin{tabular}{llllllll}
\hline No. & Gene ID & Name & $\begin{array}{l}\text { Protein } \\
\text { Length (aa) }\end{array}$ & $\begin{array}{l}\text { Gene } \\
\text { Length (bp) }\end{array}$ & Chr & $\begin{array}{c}\text { Tandem } \\
\text { Localization } \\
\text { predicted }\end{array}$ \\
\hline 44 & Bol023729 & BoHSP70-44 & 112 & 4378 & Scaffold000098 & NO & Mit/N \\
45 & Bol011835 & BoHSP70-45 & 215 & 648 & Scaffold000206 & NO & Mit \\
46 & Bol011837 & BoHSP70-46 & 308 & 927 & Scaffold000206 & NO & NO \\
47 & Bol003943 & BoHSP70-47 & 169 & 1213 & Scaffold000335 & NO & Cyt \\
48 & Bol003401 & BoHSP70-48 & 360 & 1733 & Scaffold000351 & NO & Cyt \\
49 & Bol003004 & BoHSP70-49 & 377 & 1372 & Scaffold000367 & Cyt \\
50 & Bol002682 & BoHSP70-50 & 367 & 2872 & Scaffold000379 & NO & Chl/N \\
51 & Bol002311 & BoHSP70-51 & 143 & 931 & Scaffold000394 & Scaffold000470 & Cyt \\
52 & Bol001093 & BoHSP70-52 & 377 & 1605 & &
\end{tabular}

of the protein and biological macromolecules to improve the resistance of the plant [7]. In addition, some studies found that the HSP protein has some relationship with plant embryogenesis. Cordewener et.al studied the embryonic development of Brassica napus revealing that heat shock at $32^{\circ} \mathrm{C}$ for $8 \mathrm{~h}$ was associated with a few de novo synthetic 70-kDa HSPs: HSP68 and HSP70, the HSP70 family was upregulated by heat shock stimulation [13]. The relationship between heat shock treatment and embryogenesis was also studied in Brassica napus, and HSP70 and HSP90 located in the nucleus and cytoplasm were found to be rapidly induced [14].

There are relatively few studies on the roles of HSP70s in the development of organisms, HSP70s are also essential during normal growth. Duck et al. found that HSP70 transcripts were detected in mature anthers in tomato [15]. Sung et al. found that $H S P 70-1,-2$, and -3 were widely expressed in the roots, leaves, stems, flowers, and siliques, but HSP70-4 was only expressed in roots and leaves, and HSP70-5 was not detected in any tissues of Arabidopsis [16]. The cpHSP70s maintain chloroplast structure and function and orchestrate plant development $[17,18]$. In addition, cpHSP70s and mtHSP70s act as part of a chaperone to help precursor proteins translocate to their individual destinations [19].

HSP7O has been identified in many plants. Arabidopsis contains at least 17 genes encoding members of the HSP70 family proteins [16], while at least 26 members in rice [20], 12 members in spinach [21], and 61 putative HSP70 members in soybean were found [22]. Cabbage (Brassica. oleracea var. capitata) is one of the most important vegetable crops in the world. As quite few studies have been conducted on cabbage HSP70 family genes, we know little about their functions in growth and the response to environmental stress tolerance to heat shock. Thus, a genome-wide analysis of the BoHSP70 genes will help to reveal the underlying complex molecular mechanisms. The publication of the genome data of Brassica enables the systematic analyses of HSP7O evolution and function. In this study, the bioinformatics method was used to analyze genomic HSP70 gene family members of cabbage, including the number of genes, chromosomal localization, phylogenetic relationships, structural features, functional predictions and expression analysis. These results lay the groundwork for the functional identification of the HSP7O genes and its application in breeding more adaptable cabbage cultivars.

\section{Results}

Genome-wide identification of the BoHSP7O family genes in cabbage

A total of 52 BoHSP70 genes were identified and designated BoHSP70-1-BoHSP70-52 using consecutive nomenclature. Detailed information about each BoHSP70 gene is shown in Table 1. The BoHSP70s encoded proteins varied from 107 to 896 amino acids (aa) in length. Among these proteins, the BoHSP70-28 protein sequence was the shortest with 107 amino acids, and the BoHSP70-1 protein sequence was the longest with 896 amino acids. Forty of the BoHSP70 genes were distributed on all nine chromosomes with chromosomes 1 and 3 harboring the most (nine, respectively) BoHSP70 genes. The other 12 genes were located on different scaffolds and were not mapped to any chromosome. Within the 52 BoHSP70 proteins, 32 members shared the similar localization to cytosol, two to ER, ten to mitochondria, two to chloroplast, two to nucleus membrane, and four members were located in more than one compartment.

To show an overview distribution of the BoHSP70 family members, a total of 40 genes were mapped onto the nine chromosomes in cabbage (Fig. 1). Most of these genes are anchored on nine chromosomes of cabbage, primarily distributed in the chromosomal middle and end regions. The numbers of BoHSP70 genes on each chromosome are as follows: 9 on C01, 9 on C03, 4 on C04, 4 on C05, 4 on C08, 3 on $\mathrm{C} 02,3$ on C09, 2 on C06, and 2 on C07. The remaining 12 genes, including BoHSP70-41-BoHSP70-52, were not distributed on the chromosome and were located on different scaffolds. 


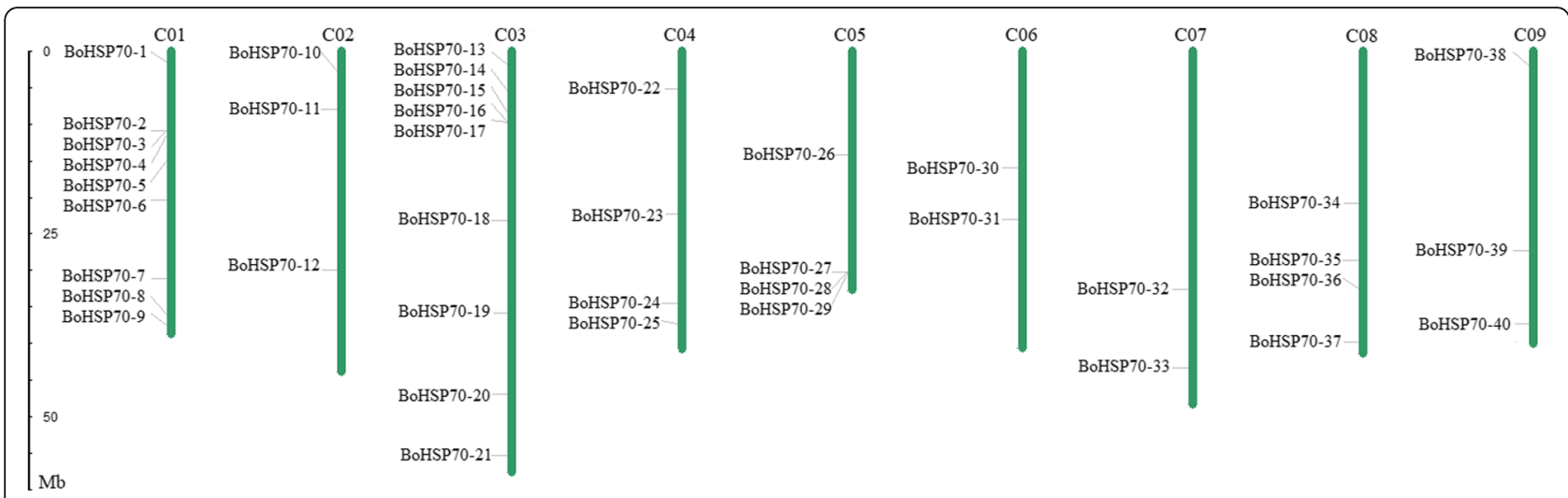

Fig. 1 Distribution of the BoHSP70 gene family members on the cabbage chromosomes. The bar located on the left side indicates the chromosome sizes in mega bases (Mb), and the scale represents the length of the chromosome

\section{Duplication and Ks analysis of the BoHSP7O genes in} cabbage

Gene duplication is one of the most important characteristics of plant genomic structure, which can occur by independent mechanisms resulting in segmental or tandem duplications. Due to the importance of gene duplications on the evolution of gene families in plants, we analyzed gene duplication of putative BoHSP70 genes in the cabbage genome. We detected one tandem and 25 segmented duplicated gene couples among the 52 identified BoHSP7O genes in cabbage (Fig. 2). A tandem duplicated gene couple was BoHSP70-25/BoHSP70-22, and

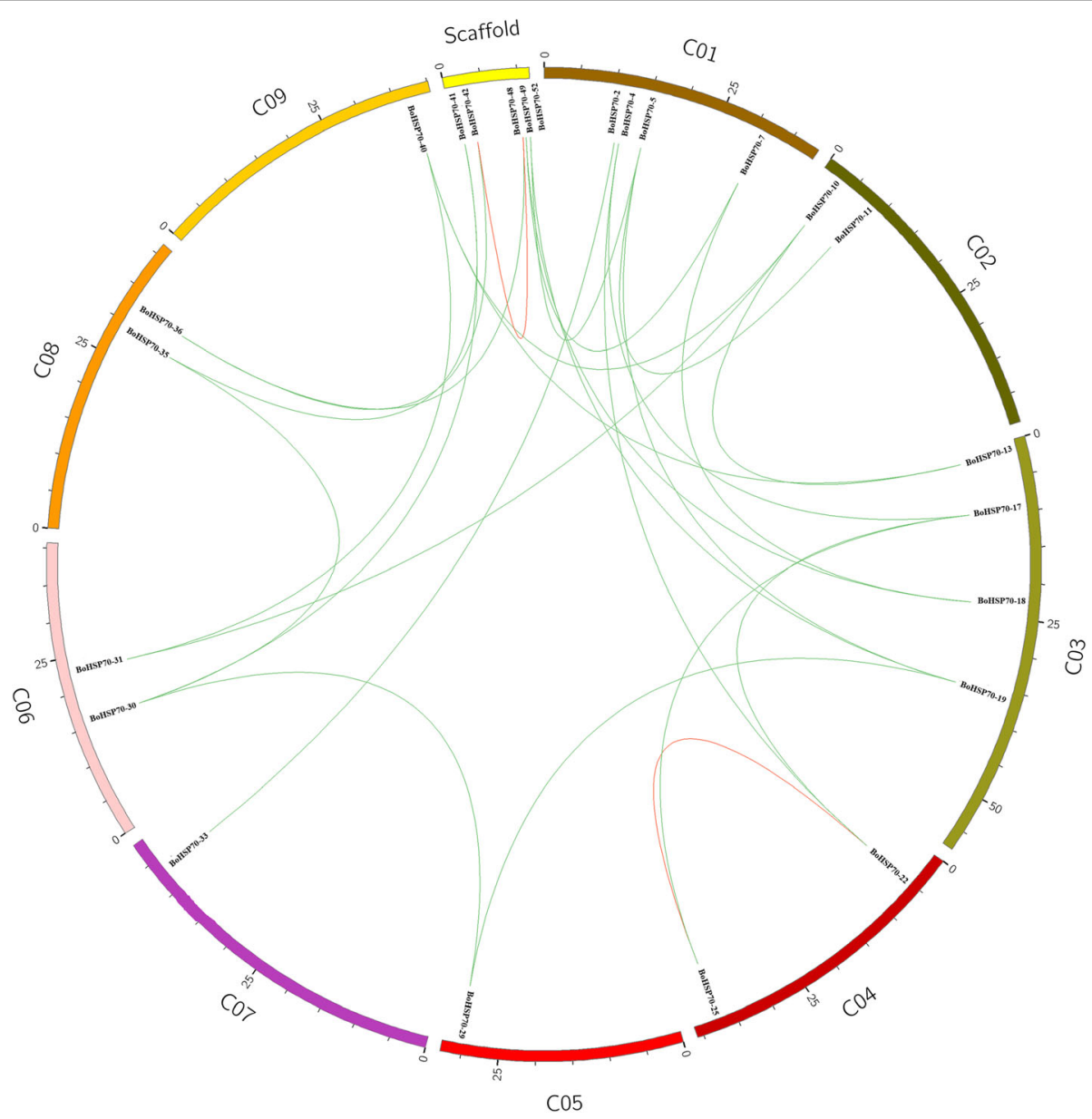

Fig. 2 Duplication of the BoHSP7O gene family members in cabbage 
segmental duplicated gene couples included BoHSP704/BoHSP70-22, BoHSP70-13/BoHSP70-10, BoHSP7025/BoHSP70-17, BoHSP70-52/BoHSP70-5, BoHSP7052/BoHSP70-19, BoHSP70-13/BoHSP70-40, BoHSP705/BoHSP70-19, BoHSP70-30/BoHSP70-41, BoHSP7035/BoHSP70-30, BoHSP70-31/BoHSP70-10, BoHSP7035/BoHSP70-41, BoHSP70-10/BoHSP70-40, BoHSP7017/BoHSP70-22, BoHSP70-4/BoHSP70-17, BoHSP7018/BoHSP70-7, BoHSP70-49/BoHSP70-7, BoHSP7049/BoHSP70-18, BoHSP70-31/BoHSP70-40, BoHSP7029/BoHSP70-30, BoHSP70-29/BoHSP70-19, BoHSP7011/BoHSP70-5, BoHSP70-36/BoHSP70-48, BoHSP7036/BoHSP70-42, BoHSP70-33/BoHSP70-2 and BoHSP7048/BoHSP70-42.

The value of $\mathrm{Ka} / \mathrm{Ks}$ can be used as an indicator for the selection pressure of a gene during evolution. Our results indicated that all the values were less than 1 , indicating that the BoHSP70 genes primarily evolved under the influence of purifying selection (Table 2).

Table 2 Ks analysis of the BoHSP70 genes in cabbage

\begin{tabular}{lllll}
\hline Paralogous pairs & Ka & Ks & Ka/Ks & MYA \\
\hline BoHSP70-25/BoHSP70-22 & 0.00468499 & 0.616754 & 0.0075962 & 44.31 \\
BoHSP70-4/BoHSP70-22 & 0.0114715 & 0.311382 & 0.0368405 & 22.37 \\
BoHSP70-13/BoHSP70-10 & 0.00460242 & 0.510366 & 0.00901789 & 36.66 \\
BoHSP70-25/BoHSP70-17 & 0.00515522 & 0.600754 & 0.00858124 & 43.16 \\
BoHSP70-52/BoHSP70-5 & 0.00379167 & 0.393786 & 0.00962874 & 28.29 \\
BoHSP70-52/BoHSP70-19 & 0.00250496 & 0.418668 & 0.00598315 & 30.08 \\
BoHSP70-13/BoHSP70-40 & 0.00473091 & 0.410763 & 0.0115174 & 29.51 \\
BoHSP70-5/BoHSP70-19 & 0.0011933 & 0.393576 & 0.00303194 & 28.27 \\
BoHSP70-30/BoHSP70-41 & 0.00507645 & 0.338896 & 0.0149794 & 24.35 \\
BoHSP70-35/BoHSP70-30 & 0.00460708 & 0.356858 & 0.0129101 & 25.64 \\
BoHSP70-31/BoHSP70-10 & 0.0288687 & 2.691 & 0.0107279 & 193.32 \\
BoHSP70-35/BoHSP70-41 & 0.00239095 & 0.371426 & 0.00643723 & 26.68 \\
BoHSP70-10/BoHSP70-40 & 0.00232753 & 0.373628 & 0.00622953 & 26.84 \\
BoHSP70-17/BoHSP70-22 & 0.00530025 & 0.2989 & 0.0177325 & 21.47 \\
BoHSP70-4/BoHSP70-17 & 0.00990488 & 0.13301 & 0.0744675 & 9.56 \\
BoHSP70-18/BoHSP70-7 & 0.00133357 & 0.262495 & 0.00508038 & 18.86 \\
BoHSP70-49/BoHSP70-7 & 0.00026549 & 0.265494 & 0.001 & 19.07 \\
BoHSP70-49/BoHSP70-18 & 0.00117001 & 0.238548 & 0.0049047 & 17.14 \\
BoHSP70-31/BoHSP70-40 & 0.0313242 & 2.7135 & 0.0115439 & 194.94 \\
BoHSP70-29/BoHSP70-30 & 0.0287632 & 1.59633 & 0.0180184 & 114.68 \\
BoHSP70-29/BoHSP70-19 & 0.0199692 & 1.70793 & 0.011692 & 122.7 \\
BoHSP70-11/BoHSP70-5 & 0.00111277 & 1.0399 & 0.00107008 & 74.71 \\
BoHSP70-36/BoHSP70-48 & 0.938473 & 1.1962 & 0.784544 & 85.93 \\
BoHSP70-36/BoHSP70-42 & 0.928543 & 1.23367 & 0.752667 & 88.63 \\
BoHSP70-33/BoHSP70-2 & 0.0425914 & 0.477849 & 0.0891316 & 34.33 \\
BoHSP70-48/BoHSP70-42 & 0.0383699 & 0.327275 & 0.11724 & 23.51 \\
\hline
\end{tabular}

Phylogenetic relationship of the BoHSP70 genes in cabbage Based on the amino acid sequence of cabbage (52), soybean (61), Arabidopsis (18), and rice (32) HSP70 proteins, the BoHSP70 proteins phylogenetic tree of the HSP70 family genes was constructed using software MEGA 5.0. According to previous studies, the AtHSP70 gene family is divided into five sub-families, rice contained six sub-families, soybean contained eight subfamilies. Therefore, based on their phylogenetic relationships, the combined cabbage, soybean, rice, and Arabidopsis phylogenetic trees can be divided into seven sub-families (class I-VII; Fig. 3). Among the seven clusters, class I was the largest, containing 52 members, and composed of four members from cabbage, 30 from soybean, 12 from rice, and six from Arabidopsis. Class II contained 16 members (four cabbage, four soybean, five rice, and three Arabidopsis members). The HSP70 members in Class III were two cabbage, six soybean, nine rice, and four in Arabidopsis. Class IV was a small sub-family, which only included three cabbage, one Arabidopsis, two soybean, and one rice member. Class V contained four cabbage, ten soybean, four rice, and four Arabidopsis members. Class VI contained five cabbage, one rice and nine soybean members. Class VII only contained 30 cabbage members, no soybean, rice, and Arabidopsis members. Excepted Class VII, all of the other sub-families contained rice, Arabidopsis, and soybean HSP70 genes, those 30 cabbage members in Class VII are all located in the cytoplasm. In Class I-V, 18 members from Arabidopsis are mostly related to external stress, At5g49910 and At4g37910 act redundantly in the thermotolerance of germinating seeds, BoHSP70-12, $9,6,8,43,37,15,16,3,20,24,2,33,44,45$, and 46 may be related to stress, other family members in Class VI and VII may have other unknown functions.

\section{Structural analysis of the BoHSP70 genes}

Based on the coding sequence of the BoHSP70 genes, the structure of these genes was plotted using the online tool GSDS. Figure 4 provides a detailed illustration of the relative lengths of the introns and the conservation of the corresponding exon sequences within each BoHSP70 gene. The number of introns in all these genes ranged from 0 to 23. Most of the BoHSP70 genes contain three to eight introns, while BoHSP70-26 has 23 introns, BoHSP70-45 and BoHSP70-46 lack introns. There are also large differences in the position and length of the introns.

To better understand the structural characteristics of the BoHSP70 proteins, ten consensus motifs were found in the BoHSP70 proteins using the MEME motif search tool, and the distribution of these conserved motifs in the BoHSP70 proteins was analyzed further. The results showed that most of these genes contained eight 


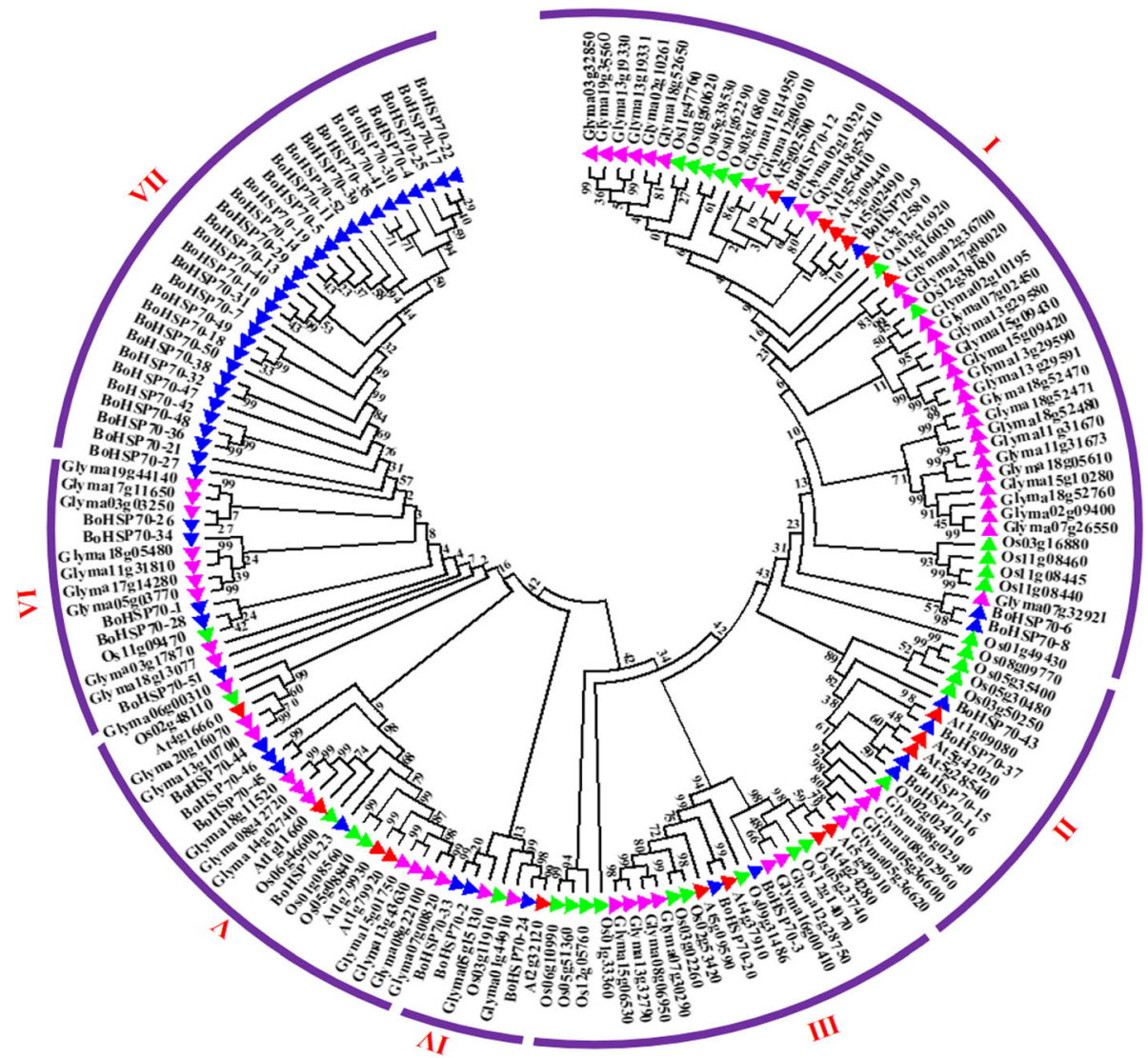

Fig. 3 Phylogenetic tree of the HSP70 proteins from cabbage, Arabidopsis, rice, soybean. For the cabbage (prefixed by Bo) HSP70 proteins, gene names were used; the IDs of Arabidopsis (prefixed by At), rice (prefixed by Os), and soybean (prefixed by Glyma) HSP70 proteins were used

conserved motifs, which is missing up to 45 genes. Most of the closely related genes exhibit similar motif compositions, suggesting functional similarities in the BoHSP70 family. The BoHSP70-1, BoHSP70-2, BoHSP70-6, BoHSP70-8, BoHSP70-9, BoHSP70-12, ВoHSP70-15, BoHSP70-16, BoHSP70-20, BoHSP70-21, BoHSP70-24, BoHSP70-33, BoHSP70-37, BoHSP70-43, and BoHSP7047 genes had only one to two motifs. These results imply that the composition of the structural motifs varies among different members of the BoHSP7O family genes but is similar within closely related genes.

\section{Expression patterns of the BoHSP7O genes in various tissues and $\mathrm{qRT}-\mathrm{PCR}$ validation}

To obtain expression profiling of the BoHSP7O genes, RNA-seq data from seven tissues (roots, stems, leaves, buds, flowers, calluses and siliques) were used in the expression analysis. As a result, a higher expression level of the BoHSP7O genes was observed in bud tissue than the other tissues (Fig. 5). Those 52 identified BoHSP70 genes were actively expressed in at least one of the six tissues (Fig. 5). High expression levels of BoHSP70-30, BoHSP70-19, BoHSP70-22, BoHSP70-17, BoHSP70-25,
BoHSP70-52, and BoHSP70-5 were observed in the buds. BoHSP70-12, BoHSP70-4, BoHSP70-44, BoHSP7046, and BoHSP70-37 were observed in calluses. BoHSP70 28 and BoHSP70-34 were observed in the leaves. BoHSP70-49 was observed in the stem, indicating its putative functions in the development and other physiological processes in buds. Nine BoHSP70 genes were only upregulated in the buds (BoHSP70-14, BoHSP70-30, BoHSP7019, BoHSP70-22, BoHSP70-17, BoHSP70-25, BoHSP70-5, BoHSP70-41, and BoHSP70-52), and four in calluses (BoHSP70-12, BoHSP70-4, BoHSP70-6, and BoHSP70$44)$. The genes that are highly expressed in plant tissues or organs are often found to be able to regulate target genes involved in the processes of plant growth and development.

In this study, we identified development-related BoHSP70 genes at the transcription level in the cabbage genome, and nine genes (BoHSP70-5, 14, 17, 19, 22, 25, 30,41 , and 52) were selected in buds that were upregulated, downregulated or not different in other tissues based on the normalized FPKM values. qRT-PCR was conducted to verify the gene expression patterns of the BoHSP7O in six different tissues, including bud, leaf, stem, callus, flower and root. BoHSP70-5, 14, 17, 19, 22, 


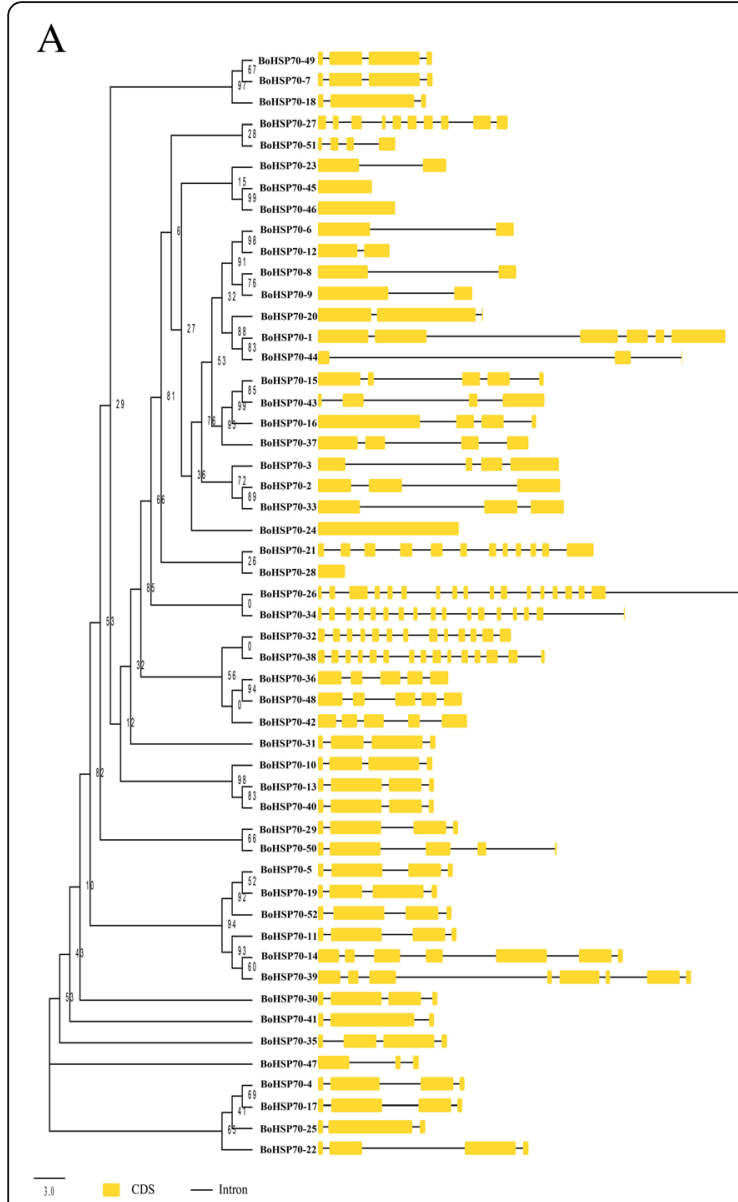

B

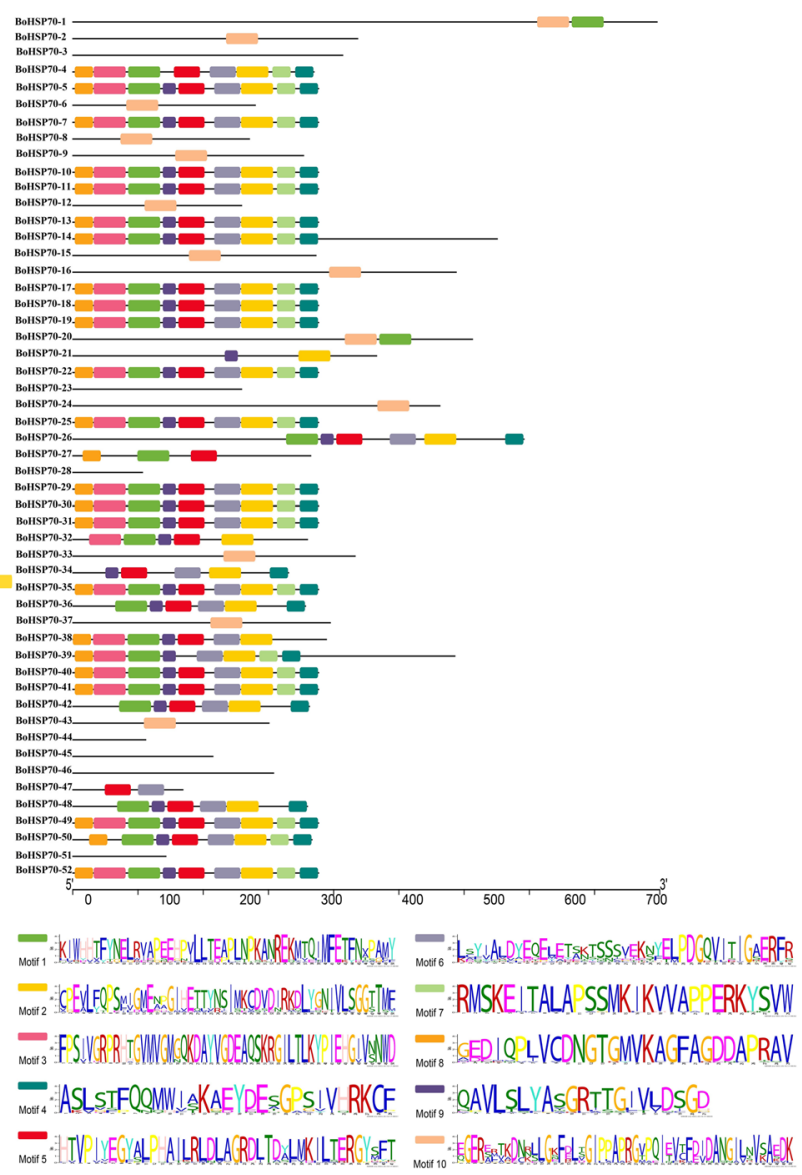

Fig. 4 Gene structure and conserved motif analysis of the BoHSP70 genes. a Gene structure of the BoHSP70 genes in cabbage. b Motif compositions of BOHSP70. c Conserved motifs in BOHSP7O were detected with MEME. Ten different motifs are represented by variously colored boxes

$25,30,41$, and 52 were primarily expressed in the buds. These transcripts could hardly be detected in leaves, flowers, and calluses, which was consistent with the results from RNA-seq analysis. Thus, we further confirmed their preferential expression as shown in Fig. 6 . From this result we can find that eight genes detected by qRT-PCR are roughly consistent with the RNA-seq analysis, which further confirmed their preferential expression.

\section{Expression patterns of the BoHSP70 genes in different periods of fertile and sterile buds and QRT-PCR verification} We found that some BoHSP7O genes were specifically expressed in buds from the heat map in different tissues. To verify the specific role of these genes in flower development, RNA-seq data from six samples divided into three stages based on the developmental stages of the male gamete in which the female gamete is normal (f2: tetrad stage of the fertile buds, f3: microspore period, f4: binuclear phase; s2: tetrad stage of the sterile buds, s3: microspore period sterile, and s4: binuclear phase sterile) were used in the expression analysis. As shown in Fig. 7, BoHSP70-5, 17, 19, 22, 25 and 52 were highly expressed at the binuclear phase (f4), while the low level of expression at the binuclear phase was significant (s4). BoHSP70-41 had a significant low level of expression at the microspore period (f3).

In this study, we identified developmental-related BoHSP70 genes at the transcriptome level in the cabbage genome, and six genes (BoHSP70-5, 17, 19, 22, 25, and 52) were selected in buds that were upregulated at the fertile binuclear phase, while they were downregulated at the sterile binuclear phase based on the normalized FPKM values. qRT-PCR was conducted to verify the gene expression patterns of BoHSP70 at the binuclear phase. As shown in Fig. 8, in the binuclear phase, all six genes were highly expressed in the fertile buds compared to the sterile buds. These results were consistent with the data of the RNA-seq analysis, and the high expression of BoHSP7O in f4 is likely to be highly expressed in stamens. Thus, those genes may be involved in stamen development. 


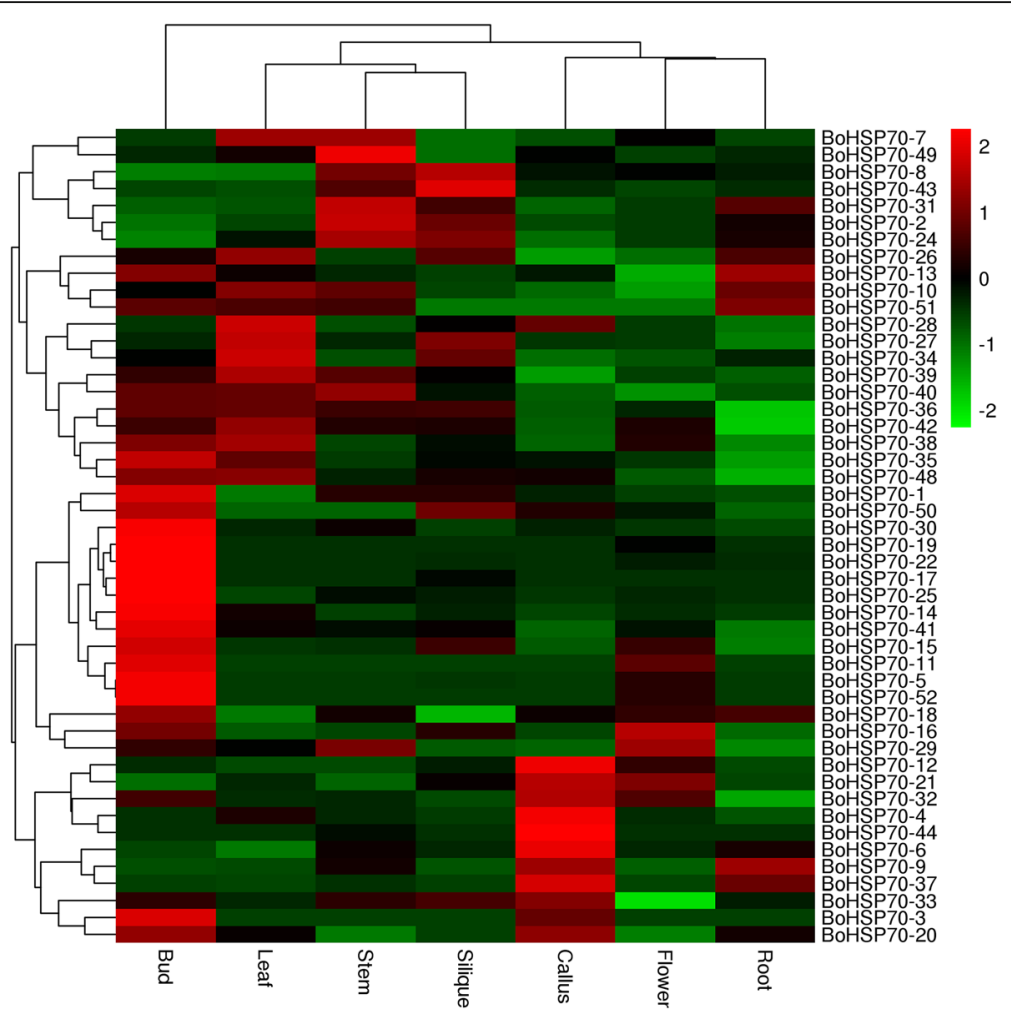

Fig. 5 Heat map representation and hierarchical clustering of BOHSP70 genes expression levels across roots, callus, siliques, stems, leaves, buds, and flowers

\section{Subcellular localization of BoHSP70-5}

Based on the results of the expression in different periods of buds (Fig. 7 and Fig. 8.), the BoHSP7O-5 gene expression in fertile was 40 times higher than that in sterile buds, the difference was significant between fertile and sterile buds. In silico subcellular localization prediction using Plant-mPLoc suggested that BoHSP70-5, 17, $19,22,25$ and 52 proteins were localized in the cytoplasm. To further characterize the subcellular localization of the BoHSP70-5 gene, was introduced into the pBWA(V)HSGFP translational fusion construct. The recombinant pBWA(V)HS-HSP70-5-GFP fusion was infiltrated into the protoplast cells of Arabidopsis. pBWA(V)HS-GFP was used as a positive protein control and was detected in the nucleus and cytoplasm (Fig. 9 d). The GFP signal of BoHSP70-5 was observed exclusively in the cytoplasm, suggesting that this BoHSP70-5 was a cytoplasmic protein (Fig. $9 \mathrm{D}$ ), consistent with the in silico prediction results.

\section{Discussion}

A previous analysis of the HSP70 gene family was performed in the model plant Arabidopsis thaliana [23, 24]. However, this gene family has not been systematically characterized in cabbage. Therefore, we performed a whole-genome analysis of the BoHSP70 gene family in cabbage, including an analysis of their phylogeny, chromosomal location, gene structure, conserved motifs and expression profiles. Based on the phylogenetic, gene structure, and motif analysis of the BoHSP7O genes in cabbage, we discovered that the most closely related members in the same categories share similar exon/intron structures and intron numbers, which was similar to the HSP70 family genes in soybean [13]. For example, in the class I, BoHSP7O members contain two exons, while those in the class VII subfamily contain more than four exons. In the terminal branch of the phylogenetic tree, the number of exons/introns was similar in one of the sister pairs. However, there was still one sister pair that showed changes in their intron/exon structure and numbers, for example, BoHSP70-2 and BoHSP70-3. These findings indicated that some intron loss, along with intron gain events, might have occurred during the structural evolution between the two families of the BoHSP70-encoding genes. The same situation was also revealed using motif analysis, and the type and number of motifs were similar in proteins within the same subfamily but differed from the proteins in the other subfamilies.

We also investigated gene duplication events to further understand the expansion mechanism of the BoHSP7O family genes. The duplications of individual genes, chromosomal segments, or entire genomes have been 


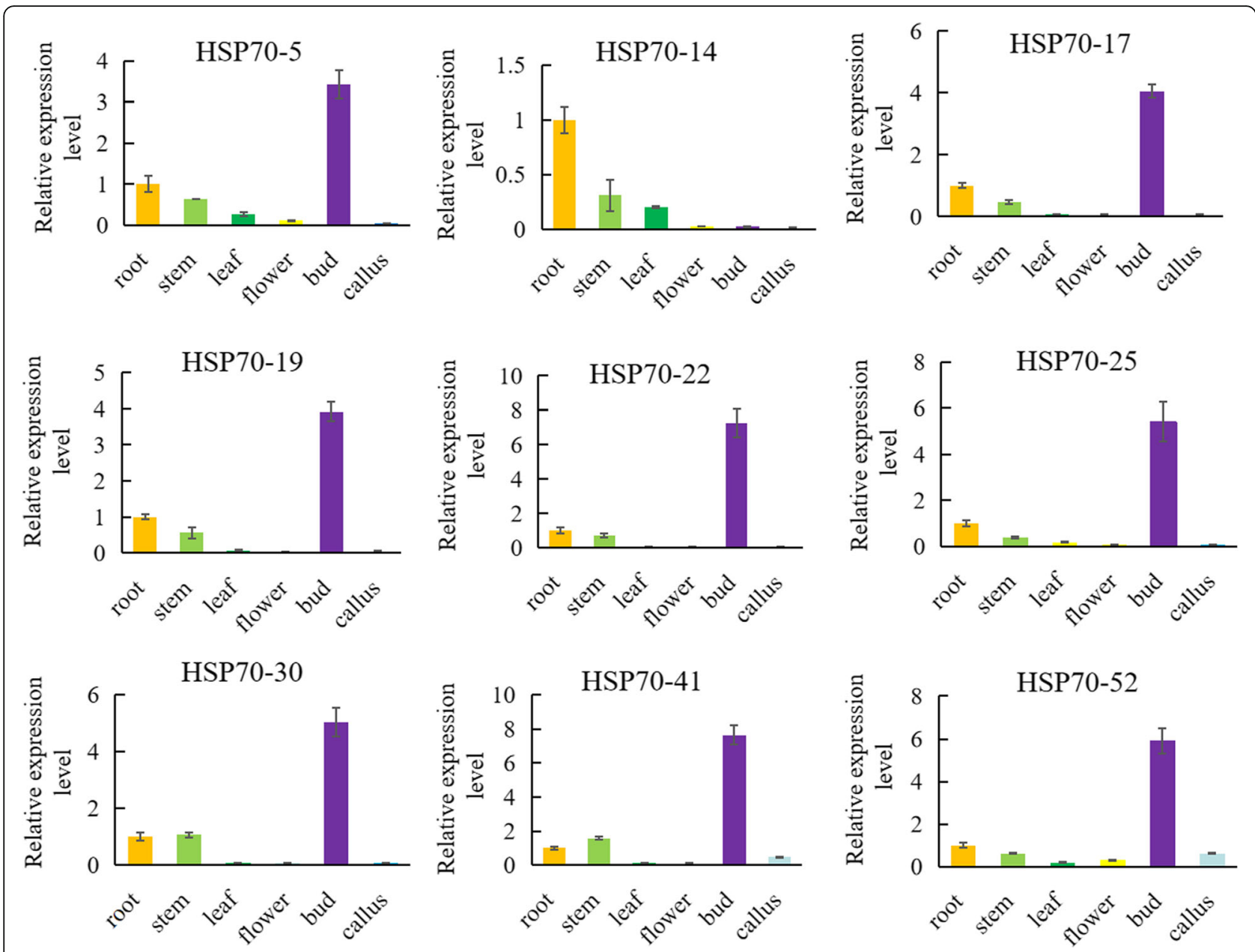

Fig. 6 Expression analysis of the BoHSP70 genes in different tissues. QRT-PCR analysis of the BoHSP70 transcript levels in the roots, stems, leaves, flowers, buds and calluses. Data are presented as the means \pm SD

major forces in the evolution of plant genome structure and content during the process of genome evolution [25-28]. A tandem duplication event is confirmed by the presence of two or more neighboring genes on the same chromosome, while a segmental duplication event is defined as a gene duplication on different chromosomes [29]. This study indicates that the BoHSP70 family genes possess a higher whole genome duplication ratio $(46 \%$, 24 of 52 genes) and a lower tandem duplication ratio (4\%, 2 of 52 genes) in cabbage. This is consistent with a previous study showing that tandem duplications have been rare in the expansion of the GRF, HSP and HSF families $[30,31]$. To verify whether Darwinian positive selection was involved in the HSP7O gene divergence after duplication, the nonsynonymous (Ka) versus synonymous (Ks) substitution rate ratios were calculated for the 26 paralogous pairs [32]. A Ka/Ks ratio significantly lower than 0.5 suggests a purifying selection for both duplicates. The low $\mathrm{Ka} / \mathrm{Ks}$ ratio indicates that all the gene pairs, with the exception of two (BoHSP70-36/
BoHSP70-48 and BoHSP70-36/BoHSP70-42), might have evolved under the influence of purifying selection.

An analysis of gene expression patterns can be used to some extent to predict the molecular functions of genes involved in different processes [33]. A previous study established that HSP70s are expressed in different tissues and organs and are also expressed when treated with salt, drought and heat [34-38]. Our heatmap data showed that most BoHSP70 genes were expressed in different cabbage tissues. These results indicate that they may participate in growth and development. It was determined that most of the paralogous pairs with high sequence similarity had similar expression patterns in different tissues. For instance, the BoHSP70-5 and BoHSP70-52 pair, the BoHSP70-5 and BoHSP70-19, BoHSP70-5 and BoHSP70-11, and BoHSP70-35 and BoHSP70-41 pairs showed strong expression in the bud. A divergence in expression was also found in the paralogous pairs. For example, in the BoHSP70-13 and BoHSP70-40 pair, BoHSP70-13 was highly expressed 


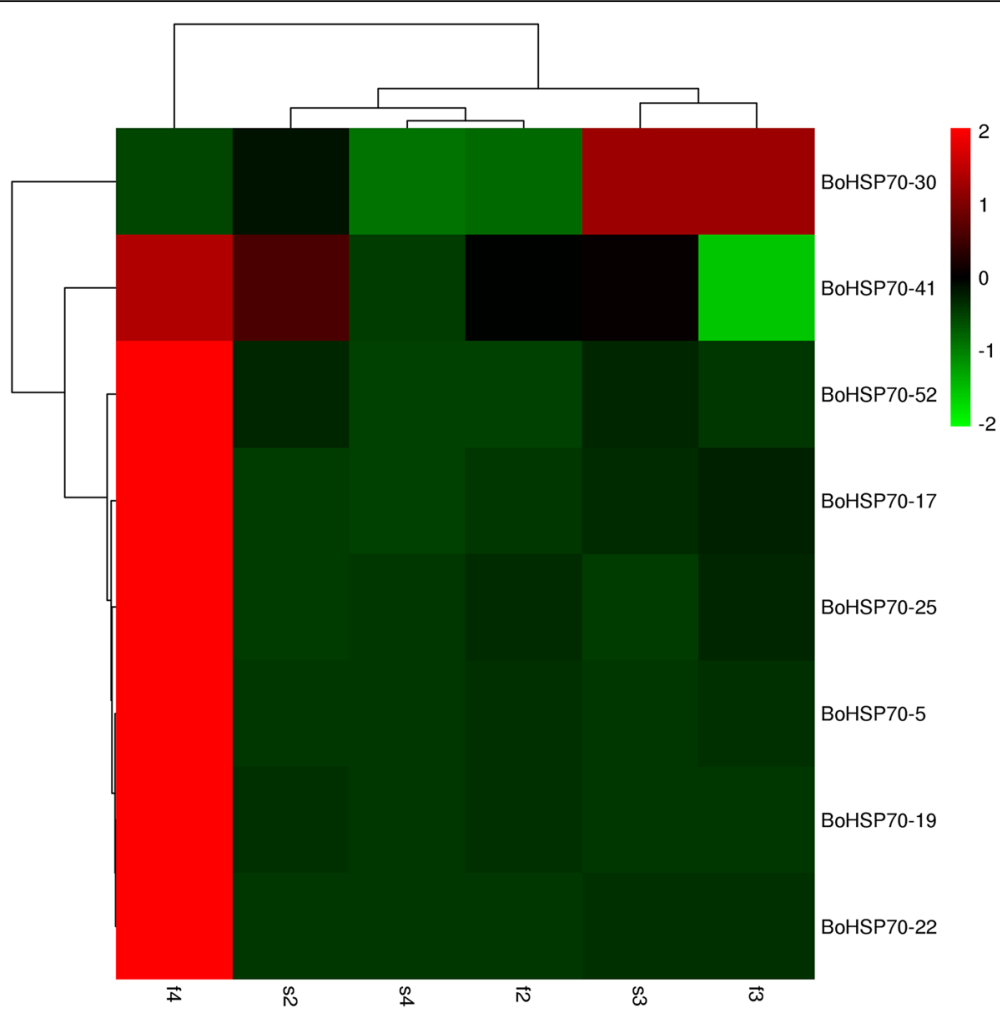

Fig. 7 Heat map representation and hierarchical clustering of BoHSP7O genes expression levels in different periods of cabbage bud. f2: tetrad stage of the fertile buds, f3: microspore period of the fertile buds, f4: binuclear phase of the fertile buds, s2: tetrad stage of the sterile buds, s3: microspore period of the sterile buds, s4: binuclear phase of the sterile buds

in the roots, flowers and buds, with little or no expression in the other tissue types. However, its para$\log$, BoHSP70-40, was not only expressed in the roots, flowers and buds but also had obvious expression in the stems. It is interesting to note that nine genes were highly upregulated in buds and downregulated in the other five tissues, which indicates that those genes might be primarily involved in bud growth. However, the gene expressions profiles, which in the different tissues usually tended to be different, some bud-regulated genes were downregulated in the flowers and roots, which indicated that two sets of BoHSP70 genes were involved in tissue development, respectively.

For the BoHSP70 gene members, we were particularly interested in those that might play crucial roles in bud development. Sheoran et al. and Frank et al. indicated that both low and high molecular weight HSPs have been found to be expressed in the early and late stages of pollen development in various plant species [39, 40]. One hypothesis is that the activation of HSP gene expression during plant development is correlated to developmental programs rather than to the response of the plant under stressful environmental conditions [41, 42]. During pollen formation, HSPs may function as molecular chaperones for the folding/refolding of proteins involved in meiosis and tetrad formation [43]. In this study, RNA-seq data from six samples divided into three stages based on the developmental stages of the male gamete in which the female gamete is normal were used in the expression analysis. Those six BoHSP70 genes in different periods of buds revealed that BoHSP70-5, 17, 19, 22, 25, and 52 were highly expressed at the binuclear phase in fertile buds (f4), low or no expression in other bud periods (f2, s2, f3, s3, s4) suggesting that those genes may be involved in pollen development, especially binuclear pollen. According to evolutionary classification, these six genes are family-specific genes in cabbage, which are far from homologous with Arabidopsis thaliana, therefore, subcellular localization was performed by selecting BoHSP7O-5 of 40-fold different expression between fertile and sterile buds, the result showed that BoHSP70-5 was a cytoplasmic protein. Further experimental validations would broaden the understanding of the BoHSP70 functions in stamen development at binuclear pollen.

\section{Conclusions}

The cabbage (Brassica oleracea L.) genome contains 52 members of the BoHSP7O family genes. Our research in this study identified and characterized the BoHSP7O 


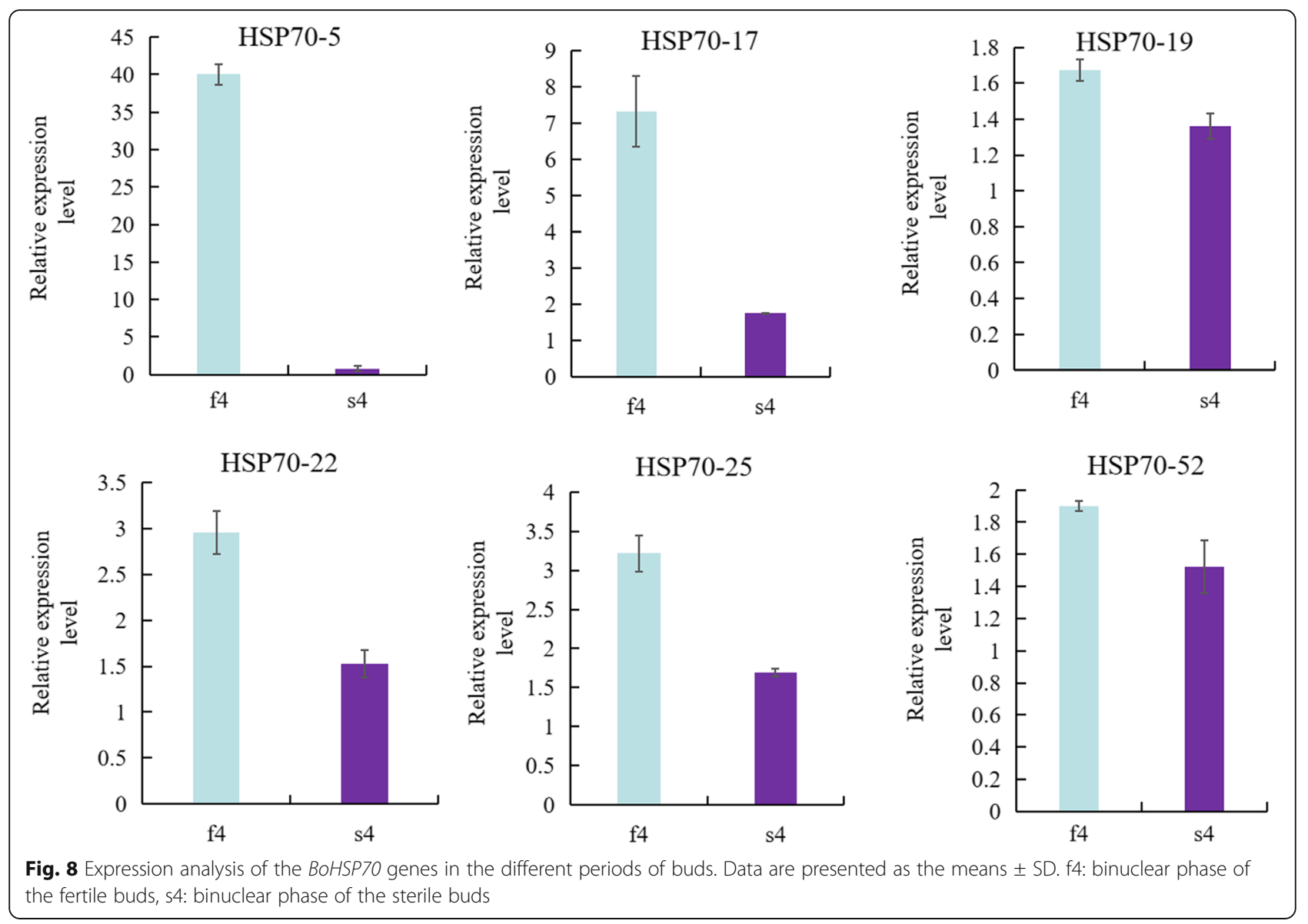

family genes and evaluated their gene and motif structures, their evolutionary histories, and their expression patterns in various cabbage tissues and different period of buds. Our findings will be helpful for further studies on the functions of these important transcription factors in various growth and developmental processes in cabbage. The overall description of this family genes and its potential involvement in pollen growth and development will facilitate further research on the HSP7O family genes, particularly in regards to their evolutionary history and biological functions.

\section{Methods}

\section{Genome-wide identification of the BoHSP70 genes}

The whole-genome cabbage protein sequences were downloaded from the Brassica oleracea Genomics Database (www.ocri-genomics.org/bolbase/blast/blast.html). The Hidden Markov Model was download from the Pfam (http://www.sanger.ac.uk/Software/Pfam/) database (Pfam:PF00012) and used, and the protein data were scanned using hmmer 3.0 [44]. The first part of the candidate genes was obtained by preliminary screening according to an e-value $<0.01$. To obtain the second part of the candidate gene, the HSP70 protein sequences of
Arabidopsis were downloaded from the NCBI (https:// www.ncbi.nlm.nih.gov/) as a query and submitted as a query in a BLASTP $(P=0.001)$ search. The results were screened with the criteria of an e-value $<10 \mathrm{e}^{-10}$ and match length $>100$. The two candidate gene sets were combined; the protein sequence of the candidate gene was scanned using NCBI-CDD search (https://www. ncbi.nlm.nih.gov/cdd), and the family members are further identified based on the domain. The subcellular locations were predicted using Cell-PLoc 2.0 (http://www. csbio.sjtu.edu.cn/bioinf/Cell-PLoc-2/) [45].

\section{Conserved motif and gene structure analysis of the BoHSP70 genes}

The amino acid sequences were subjected to "predict the domain and motif analyses" online using MEME (http://meme.sdsc.edu/meme/website/intro.html) [46], with the following parameters: number of repetitions: any; maximum number of motifs: 15 ; and the optimum motif widths: 6-200 amino acid residues. The nucleotide sequence and genomic sequence of the HSP70 gene were stored in FASTA format, and the online tool Gene Structure Display Server (GSDS) was used to draw the gene exon-intron structure (http://gsds.cbi.pku.edu.cn/) [47]. 


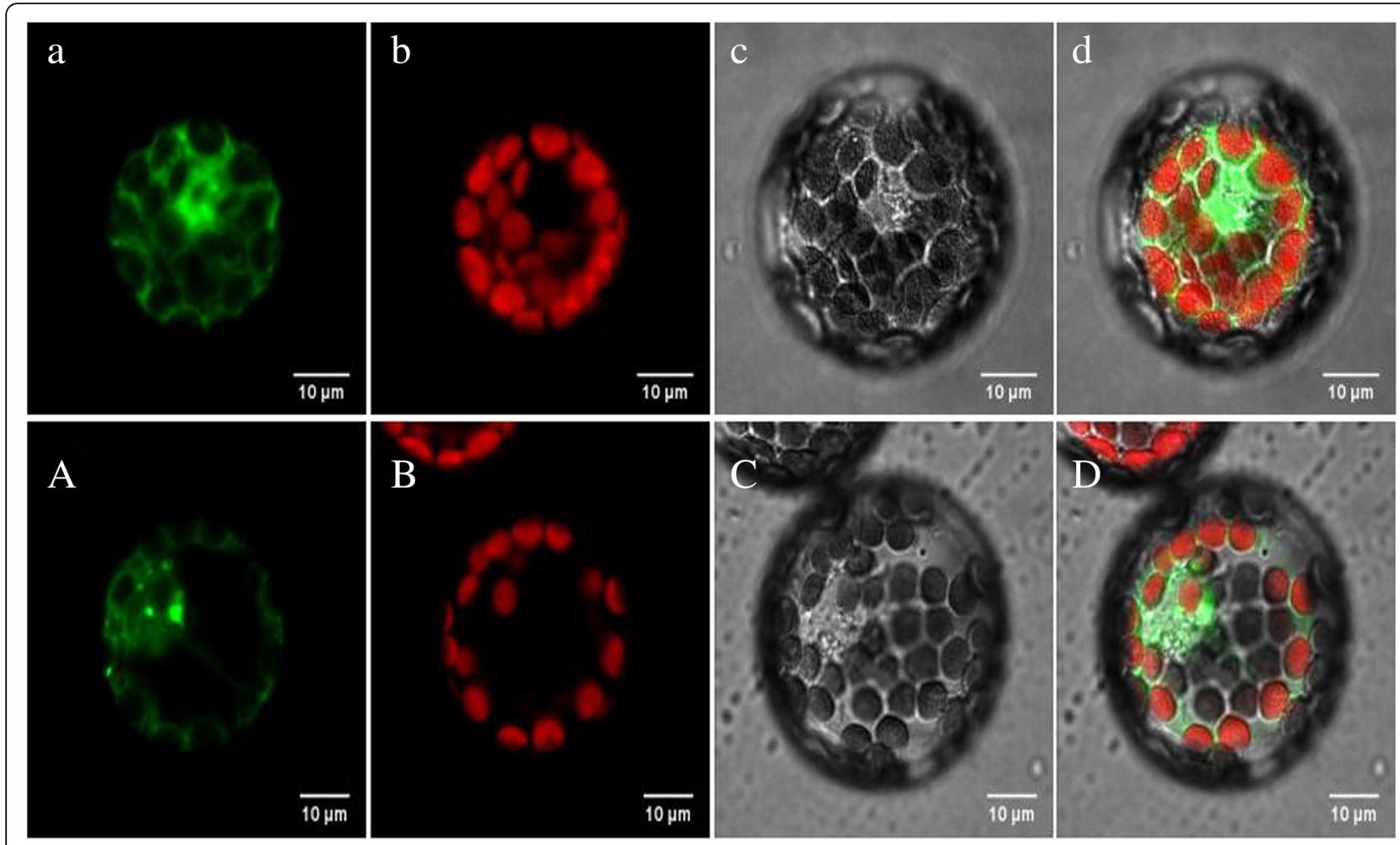

Fig. 9 Subcellular localization of BOHSP70-5 in Arabidopsis protoplast. a, b, c, d: Control GFP channel, Chloroplast channel, Bright, and Merge. A, B, C, D: Target protein GFP channel, Chloroplast channel, Bright, and Merge

\section{Construction of the phylogenetic tree}

Based on the protein sequence, we used ClustalW to simultaneously align using MEGA5.0 to construct a phylogenetic tree based on the results of the joint $\mathrm{NJ}$ (Neighbor-join) (bootstrap $=1000)$, combined with cabbage, Arabidopsis, soybean and rice data (Additional file 1: Table S1) for phylogenetic tree analysis [48], the protein sequences of Arabidopsis, soybean, and rice HSP70 were acquired from Phytozome (Joint Genome Institute, JGI) (https://phytozome.jgi.doe.gov/pz/portal.html).

\section{Localization analysis of the BoHSP70 genes}

The chromosomal distribution image of the BoHSP70 genes was generated using Map Chart software based on the chromosomal position information provided in the genomic annotation file. Some of the genes located in the scaffold failed to be mapped to chromosomes, and random genes were not shown in the image [49].

\section{Gene doubling duplication and $\mathrm{Ka} / \mathrm{Ks}$ analysis}

Gene doubling and tandem (tandem repeat) were performed using MCSCANX, and selected doubling events related to family genes were performed using Circos mapping, while providing the number of doubled genes (collinearity analysis - gene doubling analysis) and tandem genes (gene doubling analysis - tandem repeat analysis) [50]. The $\mathrm{Ka} / \mathrm{Ks}$ analysis of the HSP70 family genes was conducted using DNASPv5 [51].

\section{Expression analysis of the BoHSP70 genes using the RNA-seq data}

To assay the BoHSP70 gene expression profiles, Illumina RNA-seq data of various tissues, including roots, stems, leaves, bud, flowers, calluses and siliques were downloaded from the NCBI (GSM1052958-964). To normalize the gene expression values, the fragments per $\mathrm{kb}$ of exon per million mapped reads (FPKM) algorithm was used in this study. The gene expression levels were calculated using the FPKM value, and the default empirical abundance threshold of 1 FPKM was used to evaluate whether a gene was positively expressed or not. Finally, BoHSP70 gene expression profiles were displayed in Additional file 2: Table S2 and Additional file 3: Table S3, and the heat maps of hierarchical clustering were constructed in the Omics Share (www.omicshare.com/tools/Home/Index/ index.html).

\section{RNA isolation, CDNA synthesis and quantitative real-time} PCR analysis

The total RNAs of different developmental stages of the flowers of the two cabbage cultivars were extracted using an RNA Prep Pure Plant Kit (Takara, Dalian, Liaoning 
Province, China), and reverse-transcribed using Superscript III Reverse Transcriptase (Takara) following the manufacturer's instructions, and the cDNA was diluted to $50 \mathrm{ng} / \mathrm{L}$ with $\mathrm{ddH}_{2} \mathrm{O}$ for further examination. Realtime quantitative PCR (qRT-PCR) was conducted using SYBR Green Supermix (Takara) with a total volume of a $10 \mu \mathrm{L}$ reaction system on a CFX Connect TM Real-Time PCR Detection System (Bio-Rad, Hercules, CA, USA). These nine predicted BoHSP70s were selected based on FPKM values obtained from expression analysis of BoHSP70s in the RNA-seq data, and the primer sequences are shown in Additional file 4: Table S4. All the qRT-PCR reactions were performed in three independent biological repetitions with a template-free control to check any contaminations, actin was used as the internal reference gene in cabbage. The relative expression levels were calculated using the $2^{-\Delta \mathrm{Ct}}$ method and plotted [52].

\section{Subcellular localization}

The reaction mixture $(50 \mu \mathrm{L})$ of the gene amplification consisted of $5 \mathrm{uL}$ buffer, $2 \mathrm{uLMg}^{2+}, 2 \mathrm{uL}$ dNTP, $0.5 \mathrm{uL}$ forward and reverse primer, $1 \mathrm{uL}$ cDNA template, $2 \mathrm{uL}$ $\mathrm{P}^{+}, 2 \mathrm{uL} \mathrm{P}^{-}$and $2 \mathrm{U}$ of Taq DNA polymerase (TaKaRa, Dalian, China), add $\mathrm{ddH}_{2} \mathrm{O}$ to $50 \mu \mathrm{L}$. The amplification was performed at $94^{\circ} \mathrm{C}$ for $5 \mathrm{~min}$, followed by 30 cycles of $94{ }^{\circ} \mathrm{C}$ for $30 \mathrm{~s}, 60^{\circ} \mathrm{C}$ for $30 \mathrm{~s}$, and $72{ }^{\circ} \mathrm{C}$ for $30 \mathrm{~s}$, with two final extension at $72{ }^{\circ} \mathrm{C}$ for $10 \mathrm{~min}$ and $30 \mathrm{~min}$ at 16 ${ }^{\circ} \mathrm{C}$. The full coding sequences of BoHSP70-5 were PCR-amplified with the primers F and R (Additional file 5: Table S5), the amplification products were digested with BsaI and Eco31I, then inserted into a pBWA(V)HS-GFP vector, resulting in an $\mathrm{N}$-terminal fusion with GFP under the control of the constitutive CaMV35S promoter. The fusion constructs were introduced into Arabidopsis thaliana protoplasts as previously described [53]. The fluorescence signals were detected using confocal laser-scanning microscopy C1 (Nikon, Tokyo, Japan).

\section{Additional files}

Additional file 1: Table S1. The IDs of Hsp70 genes from different plants. (XLS $338 \mathrm{~kb}$ )

Additional file 2: Table S2. FPKM values of 52 BoHsp70 genes in various cabbage tissues. (XLS $29 \mathrm{~kb}$ )

Additional file 3: Table S3. FPKM values of 8 BoHsp70 genes in different periods of buds. (XLSX $10 \mathrm{~kb}$ )

Additional file 4: Table S4. The primer sequences of 9 BoHsp70 genes used for qRT-PCR. (XLS $22 \mathrm{~kb}$ )

Additional file 5: Table S5. The primer used for cloning of BoHsp70-5. (XLS $19 \mathrm{~kb})$

\section{Abbreviations}

BLASTP: Basic local alignment search tool-protein; FPKM: Fragments per kilobase of transcript per million mapped reads; HSFs: Heat shock transcription factors; HSPs: Heat shock proteins; qRT-PCR: Quantitative real-time polymerase chain reaction; sHSP: Small heat shock proteins

\section{Acknowledgements}

The work reported here was performed in the Key Laboratory of Biology and Genetic Improvement of Horticultural Crops, Ministry of Agriculture, Beijing 100081, China.

\section{Funding}

This work was supported by grants from the National Key Research and Development Program of China (2017YFD0101804), the Science and Technology Innovation Program of the Chinese Academy of Agricultural Sciences (CAAS-ASTIP-IVFCAAS), and the earmarked fund for the Modern Agro-Industry Technology Research System, China (CARS-23).

\section{Availability of data and materials}

Data of this study have been included in the article or as additional file.

\section{Authors' contributions}

HNS and MMX collected the public dataset, perform bioinformatics analysis and also drafted the manuscript. $X L$ contributed to bioinformatics analysis and the making of all the figures and tables. HHL conceived this study and reviewed the manuscript. ZYF, LMY, YYZ, YW and MZ reviewed the manuscript. All of the authors read and approved the final manuscript.

Ethics approval and consent to participate

Not applicable

\section{Consent for publication}

Not applicable.

\section{Competing interests}

The authors declare that they have no competing interests.

\section{Publisher's Note}

Springer Nature remains neutral with regard to jurisdictional claims in published maps and institutional affiliations.

Received: 3 December 2018 Accepted: 1 May 2019

Published online: 14 May 2019

\section{References}

1. Karlin S, Brocchieri L. Heat shock protein 70 family: multiple sequence comparisons, function, and evolution. J Mol Evol. 1998:47(5):565-77.

2. Boorstein WR, Ziegelhoffer T, Craig EA. Molecular evolution of the HSP7O multigene family. J Mol Evol. 1994;38(1):1-17.

3. Gupta RS, Golding GB. Evolution of HSP7O gene and its implications regarding relationships between archaebacteria, eubacteria and eukaryotes. J Mol Evol. 1993;37(6):573-82.

4. Wegele H, Müller L, Buchner J. Hsp70 and Hsp90-a relay team for protein folding. Rev Physiol Bioch P. 2004;151(1):1-44.

5. Young JC, Moarefi I, Hartl FU. Hsp90:a specialized but essential proteinfolding tool. J Cell Biol. 2001;154(2):267-74.

6. Pratt WB, Toft DO. Regulation of signaling protein function and trafficking by the hsp90/hsp70-based chaperone machinery. Exp Biol Med. 2003; 228(2):111-33.

7. Wang W, Vinocur B, Shoseyov O, Altman A. Role of plant heat-shock proteins and molecular chaperones in the abiotic stress response. Trends Plant Sci. 2004;9(5):244-52.

8. Zinn KE, Tunc-Ozdemir M, Harper JF. Temperature stress and plant sexual reproduction: uncovering the weakest links. J Exp Bot. 2010;61(7):1959-68.

9. Zhou SJ, Jing Z, Shi JL. Genome-wide identification, characterization, and expression analysis of the MLO gene family in Cucumis sativus. Genet Mol Res. 2013;12(4):6565-78.

10. Vacchina P, Norris-Mullins B, Carlson S, Morales M. Mitochondrial HSP70 (HSPA9B) is linked to miltefosine resistance and stress response in Leishmania donovani. Parasite Vector. 2016;9(1):621-35.

11. Maimbo M, Ohnishi K, Hikichi Y, Yoshioka H, Kiba A. Induction of a small heat shock protein and its functional roles in Nicotiana plants in the defense response against Ralstonia solanacearum. Plant Physiol. 2007; 145(1):1588-99. 
12. Vega L, Rodriguez-Silva M, Frey T. Hsp70 translocates into the plasma membrane after stress and is released into the extracellular environment in a membrane-associated form that activates macrophages. J Immunol. 2008; 180(6):4299-307.

13. Cordewener JHG, Hause G, Gorgen E, Busink R, Hause B, Dons HJM, van Lammeren AAM, van Lookeren CMM, Pechan P. Changes in synthesis and localization of members of the $70-\mathrm{kDa}$ class of heat-shock proteins accompany the induction of embryogenesis in Brassica napus L. microspores. Planta. 1995;196(4):747-55.

14. Segu-Simarro J, Testillano P, Risuenn M. Hsp70 and Hsp90 change their expression and subcellular localization after microspore embryogenesis induction in Brassica napus L. J Struct Biol. 2003;142(3):379-91.

15. Duck NB, Folk WR. HSP70 heat shock protein cognate is expressed and stored in developing tomato pollen. Plant Mol Biol. 1994;26(3):1031-9.

16. Sung DY, Ling E, Guy CL. Comprehensive expression profile analysis of the Arabidopsis Hsp70 gene family. Plant Physiol. 2001;126(2):789-800.

17. Latijnhouwers M, Xu XM, Møller SG. Arabidopsis stromal 70-kDa heat shock proteins are essential for chloroplast development. Planta. 2010;232(3):567-78.

18. Su PH, Li HM. Arabidopsis stromal 70-kD heat shock proteins are essential for plant development and important for thermotolerance of germinating seeds. Plant Physiol. 2008;146(3):1231-41.

19. Su PH, Li HM. Stromal Hsp70 is important for protein translocation into pea and Arabidopsis chloroplasts. Plant Cell. 2010;22(5):1516-31.

20. $\mathrm{Hu}$ WH, Hu GH, Han B. Genome-wide survey and expression profiling of heat shock proteins and heat shock factors revealed overlapped and stress specific response under abiotic stresses in rice. Plant Sci. 2009;176(4):583-90.

21. Guy CL, Li QB. The organization and evolution of the spinach stress 70 molecular chaperone gene family. Plant Cell. 1998;10(4):539-56.

22. Zhang L, Zhao HK, Dong QL. Genome-wide analysis and expression profiling under heat and drought treatments of HSP70 gene family in soybean (Glycine max L.). Frontiers in Plant Sci. 2015;773(6):1-15.

23. Lee JH, Schöffl F. An Hsp70 antisense gene affects the expression of HSP70/ $\mathrm{HSC70}$, the regulation of HSF, and the acquisition of thermotolerance in transgenic Arabidopsis thaliana. Mol Gen Genet. 1996;252(2):11-9.

24. Leng L, Liang Q, Jiang JJ, Zhang C, Hao YH, Wang XL, Su W. A subclass of HSP70s regulate development and abiotic stress responses in Arabidopsis thaliana. J Plant Res. 2017;130(2):349-63.

25. Sterck L, Rombauts S, Vandepoele K, Rouze P, VandePeer Y. How many genes are there in plants (...and why are they there)? Curr Opin Plant Biol. 2007;10(2):199-203.

26. Liu SG, Liu YM, Yang XH. The Brassica oleracea genome reveals the asymmetrical evolution of polyploid genomes. Nat Commun. 2014; 3930(5):1-11.

27. Semon M, Wolfe KH. Consequences of genome duplication. Curr Opin Genet 2007;09(17):505-12

28. Wang F, Dong Q, Jiang H, Zhu S, Chen B, Xiang Y. Genome-wide analysis of the heat shock transcription factors in Populus trichocarpa and Medicago truncatula. Mol Biol Rep. 2012;39(2):1877-86.

29. Swindell WR, Huebner M, Weber AP. Transcriptional profiling of Arabidopsis heat shock proteins and transcription factors reveals extensive overlap between heat and non-heat stress response pathways. BMC Genomics. 2007;8(1):125.

30. Cannon SB, Mitra A, Baumgarten A, Young ND, May G. The roles of segmental and tandem gene duplication in the evolution of large gene families in Arabidopsis thaliana. BMC Plant Biol. 2004:4(1):10.

31. Jessica AS, Lin JY, Schlueter SD, Vasylenko-Sanders IF, Shweta D, Jing Y, Roe BA, Rex TN, Brian ES, Scott AJ, Randy CS. Gene duplication and paleopolyploid in soybean and the implications for whole genome sequencing. BMC Genomics. 2007:8(1):330.

32. Omidbakhshfard MA, Proost S, Fujikura U, Mueller-Roeber B. Growthregulating factors (GRFs): a small transcription factor family with important functions in plant biology. Mol Plant. 2015;8(7):998-1010.

33. Jin Z, Liu B, Li J, Zhang L, Wang Y, Zheng HQ, Lu MZ, Chen J. Hsf and Hsp gene families in Populus: genome-wide identification, organization and correlated expression during development and in stress. BMC Genomics. 2015;16(1):181.

34. Yang $X$, Tuskan GA. Divergence of the Dof gene families in poplar, Arabidopsis, and rice suggests multiple modes of gene evolution after duplication. Plant Physiol. 2006;142(3):820-30.

35. Zhang JF, Li ZF, Jin JJ, Xie XD, Zhang H, Chen QS, Luo ZP, Yang J. Genomewide identification and analysis of the growth-regulating factor family in tobacco (Nicotiana tabacum). Gene. 2017;639:117-27.
36. Lker B, Behcet I, Emre I, Mehmet T, Sumer A, Mustafa E. Genome-wide identification of salinity responsive HSP70s in common bean. Mol Biol Rep. 2016;43(11):1251-66.

37. Guo M, Liu JH, Ma X, Zhai YF, Gong ZH, Lu MH. Genome-wide analysis of the Hsp70 family genes in pepper (Capsicum annuum L.) and functional identification of CaHsp70-2 involvement in heat stress. Plant Sci. 2016;252(2): 246-56.

38. Kurepa J, Wang S, Li Y, Smalle J. Proteasome regulation, plant growth and stress tolerance. Plant Signal and Behavior. 2009;4(1):924-7.

39. Becker JD, Boavida LC, Carneiro J, Haury M, Feijo JA. Transcriptional profiling of Arabidopsis tissues reveals the unique characteristics of the pollen transcriptome. Plant Physiol. 2003;133(2):713-25.

40. Sheoran IS, Ross AR, Olson DJ, Sawhney VK. Proteomic analysis of tomato (Lycopersicon esculentum) pollen. J Exp Bot. 2007;58(13):3525-35.

41. Waters ER, Lee GJ, Ling E. Evolution, structure and function of the small heat shock proteins in plants. J Exp Bot. 1996;47(296):325-38.

42. Sun W, Van MM, Verbruggen N. Small heat shock proteins and stress tolerance in plants. Bba-gene Struct expr. 2002;1577(1):1-9.

43. Reynolds T. Pollen embryogenesis. Plant Mol Biol. 1997;33(1):1-10.

44. Finn RD, Clements J, Eddy SR. HMMER web server: interactive sequence similarity searching. Nucleic Acids Res. 2011:gkr367.

45. Chou KC, Shen HB. Cell-PLoc: a package of web-servers for predicting subcellular localization of proteins in various organisms. Nat Protoc. 2008;3:153-62.

46. Bailey TL, Williams N, Misleh C, Li WW. MEME: discovering and analyzing DNA and protein sequence motifs. Nucleic Acids Res. 2006;34(3):369-73.

47. Hu B, Jin JP, Guo AY, Zhang H, Luo JC, Gao G. GSDS 2.0: an upgraded gene feature visualization server. Bioinformatics. 2015;31(8):1296-7.

48. Tamura K, Stecher G, Paterson D, Filipski A, Kumar S. Mega6: molecular evolutionary genetic analysis software version 6.0. Mol Biol Evol. 2007;24(8): 1596-9.

49. Voorrips RE. Map chart: software for the graphical presentation of linkage maps and QTLs. J Hered. 2002;93(1):77-8.

50. Krzywinski M, et al. Circos: an information aesthetic for comparative genomics. Genome Res. 2009;19(2):1639-45.

51. Librado P, Rozas J. DnaSP v5: a software for comprehensive analysis of DNA polymorphism data. Bioinformatics. 2009;25(5):1451-2.

52. Schmittgen TD, Livak KJ. Analyzing real-time PCR data by the comparative CT method. Nat Protoc. 2008;3:1101-8.

53. Kim J, Somers DE. Rapid assessment of gene function in the circadian clock using artificial microRNA in Arabidopsis mesophyll protoplasts. Plant Physiol. 2010;154(2):611-21.

\section{Ready to submit your research? Choose BMC and benefit from:}

- fast, convenient online submission

- thorough peer review by experienced researchers in your field

- rapid publication on acceptance

- support for research data, including large and complex data types

- gold Open Access which fosters wider collaboration and increased citations

- maximum visibility for your research: over $100 \mathrm{M}$ website views per year

At BMC, research is always in progress.

Learn more biomedcentral.com/submissions 